MATEC Web of Conferences 3, 01077 (2013)

DOI: $10.1051 /$ matecconf $/ 20130301077$

C) Owned by the authors, published by EDP Sciences, 2013

\title{
Experimental study of group IVB metals oxicarbides
}

\author{
F. Rejasse, O. Rapaud, N. Pradeilles, A. Maitre, and G. Trolliard \\ Laboratoire SPCTS, Université de Limoges, France
}

The aim of this work is to provide some experimental information within the M-C-O ternary systems (where $\mathrm{M}$ is a transition metal belonging to the IVB group). More particular, this study is devoted to the determination of the reaction and specific heats of the $\mathrm{ZrC}_{\mathrm{x}} \mathrm{O}_{\mathrm{y}}, \mathrm{TiC}_{\mathrm{x}} \mathrm{O}_{\mathrm{y}}, \mathrm{HfC}_{\mathrm{x}} \mathrm{O}_{\mathrm{y}}$ oxicarbides and of their stability domain in their respective ternary phase diagram, these data being useful to assess more accurately the corresponding ternary systems. These compounds which exhibit a FCC solid solution over a large range of temperature [1] are of interest in nuclear and high temperature applications.

So, bulk carbides and oxides were synthetized by Spark Plasma Sintering, allowing us to obtain very dense materials (close to the theoretical density). These pellets were used as carbide / oxide couples and heated to high temperatures. Chemical compositions at the equilibrium of the oxicarbide phase were then analysed in order to determine the composition and the structural evolutions of these solid solutions (the lattice parameter being directly related to the $\mathrm{C} / \mathrm{O}$ ratio).

Another way to obtain oxicarbides with specific compositions is based on the carboreduction of transition metal oxides [2, 3]. Thermal analysis (DTA and DSC) measurements were carried out during the carboreduction process from carbides and oxides powders mixtures to determine the heat of formation of the oxicarbide phase as a function of its $\mathrm{C} / \mathrm{M}$ or $\mathrm{O} / \mathrm{M}$ ratio.

These results will be used for the optimization process through the PARROT module of the Thermo-Calc software.

\section{References}

1. A.D. Mazzoni, M.S. Conconi, Materials Research 5(4) 459 (2002)

2. P. Barnier, F. Thevenot, Int. J. High Technology Ceramics 2291 (1986)

3. M. Gendre, A. Maitre, G. Trolliard, J. European Ceram. Soc. 31(13) 2377 (2011) 